\title{
A Human Capital Based Growth Model with Environment and Corruption
}

\author{
Daisuke Ikazaki
}

Received: 29 June 2014 / Revised: 10 December 2014 / Accepted: 12 December 2014 /

Published online: 24 December 2014

? 2014 Ikazaki; licensee Springer. This is an Open Access article distributed under the terms of the Creative Commons Attribution License (http://creativecommons.org/licenses/by/4.0), which permits unrestricted use, distribution, and reproduction in any medium, provided the original work is properly credited.

\begin{abstract}
In this paper, we present a simple overlapping-generations model with human capital, pollution, and political corruption to consider problems related to sustainable growth. In many growth models that incorporate the environment, it is assumed that there exists an altruistic government that enforces the environmental policy to maximize the utility of households or social welfare. The conditions for sustainable growth are derived based on this assumption. However, the assumption that the government implements appropriate policies might be overly optimistic. Bribes, political donations, and corruption might taint and skew government policy. This paper also considers politico-economic problems. We assume that environmental policy is determined endogenously through a process of bargaining between the government and the ?rm (or interest group). Corruption relaxes environmental standards, lowers the long-run growth rate, and might cause economic stagnation. The long-run growth rate might become negative if the economy is rife with corruption.
\end{abstract}

Keywords Political corruption $\perp$ Sustainable growth $\perp$ Human capital $\Perp$ Environment

JEL Classi?cation $\mathrm{O} 44 \perp \mathrm{P} 48 \perp \mathrm{Q} 20$

\section{Introduction}

As described in this paper, we present a simple overlapping-generations model with human capital, pollution, and political corruption to consider problems related to sustainable growth.

D. Ikazaki ( $\otimes)$

Faculty of Human Sciences and Design, Japan Women?s University, 2-8-1, Mejirodai, Bunkyo-ku, Tokyo, 1128680, Japan

e-mail: ikazaki@fc.jwu.ac.jp 
In earlier studies, for example, John and Pecchenino (1994), John et al. (1995), and Bovenberg and Heijdra (2002) extend the model of Diamond?s (1965) OLG model and examine the relation between growth and the environment. Stokey (1998), Aghion and Howitt (1998) also examine the relation between economic growth and the environment. ${ }^{1}$ These studies assume that the government is altruistic. Results obtained using such models suggest that environmental externalities should be internalized by environmental policies. These studies do not consider politico-economic problems. Moreover, the assumption that the government implements appropriate policies might be overly optimistic. Bribes, political donations, and corruption might taint and skew government policy. Negotiation and compromise between parties might occur when the government executes policies. Furthermore, not only government but also the private sector might use political power to head off the introduction of strict environmental policies if such policies reduce their pro?ts. ${ }^{2}$

In this paper, we will consider how political corruption affects economic growth and the environment. To highlight the dynamic features of economic activities, we use the ideas of human capital. Human capital accumulation is one of the most important factors when we consider long-run growth (Lucas 1988). Some insist that R\&D and innovation exert an important role in long-run growth (Romer 1990; Aghion and Howitt 1992). We can construct a growth model with R\&D and innovation instead of human capital. However, we can derive similar results even if we introduce R\&D. So, we assume that human capital accumulation becomes an engine of productivity improvement.

Lopez and Mitra (2000) consider the relation between pollution and growth. The amounts of donations and pollution level (environmental standard) are determined endogenously through a process of bargaining between the government and the ?rm. They show that corruption does not affect the sustainability of economic growth, although the economy emits more pollution than under the social optimum.

Our model might be interpreted as an extension of Lopez and Mitra (2000). A salient difference is that we construct a dynamic OLG model rather than a static model (Lopez and Mitra 2000 construct a static model). By constructing an OLG model, we can derive the different results from Lopez and Mitra (2000). It can be demonstrated that corruption relaxes environmental standards and lowers the longrun growth rate. Results show that the growth rate might become zero or negative if the government and/or public sector are corrupt to such a degree. Our paper specifically examines the case in which the government colludes with the entrepreneur. Their utility will increase at the expense of the laborer. In this sense, an implicit con?ict exists between entrepreneurs and laborers. ${ }^{3}$

This paper is organized as follows. In Sect. 2, the basic setting of this paper is described. In Sect. 3, we consider environmental policy. In Sect. 2 and Sect. 3, we do not take bribes or political donations into consideration. In this case, the long-run growth

\footnotetext{
${ }^{1}$ Stokey (1998) and Aghion and Howitt (1998) assume individuals with in?nite longevity. Their models are not the OLG model.

${ }^{2}$ See Fredriksson (1997), Aidt (1998). Furthermore, Damania et al. (2003) discuss the linkages between trade policy, corruption, and environmental policy.

${ }^{3}$ In Wagner (1998), Jones and Manuelli (2001), and Ono (2005), a con?ict exists between generations.
} 
rate becomes positive and the environment improves over time if certain conditions are met. In Sect. 5, problems related to political corruption are introduced. The entrepreneurs offer political donations to the government if such donations can increase their pro?ts to a great extent. However, the government accepts donations if the net bene?t of taking political donations is positive. We assume that the amount of donations and the pollution level (environmental standards) are determined endogenously through a process of bargaining between the government and the entrepreneur. In this case, the government and the ?rm try to arrive at a cooperative outcome through mutual agreement. We show that this interlocking relation between entrepreneurs and government lowers the growth rate. The economy might stagnate if the economy is heavily tainted by corruption.

\section{The Model}

First, we will analyze the ?nal goods sector. The market for ?nal goods is assumed to be perfectly competitive. A continuum of ?rms exists. Because the technology displays constant returns to scale, the precise number of ?rms is irrelevant. For simplicity, we will take their total mass to be one. Following Copeland and Taylor (1994) and Stokey (1998), we assume that the output of the ?nal good can be written as a function of pollution and effective input (in our model, human capital). We establish the production function of the ?nal good as

$$
Y_{t}=A H_{t}^{\alpha} D_{t}^{1 \perp \alpha},
$$

where $Y_{t}$ is the aggregate output, ${ }^{4} A$ denotes the productivity parameter, $H_{t}$ represents the human capital, and $D_{t}$ signi?es the pollution. The parameter $\alpha$ is assumed as $0<\alpha<1$. Presuming that the government distributes permits uniformly across ?rms and then allows a secondary market in those permits, then those ?rms maximize their pro?ts at each date, taking the wage rate $w_{t}$ and the price of permit $\tau_{t}$ as given. The pro?t of the ?rm is given as

$$
\pi_{t}=A H_{t}^{\alpha} D_{t}^{1 \perp \alpha} \perp w_{t} H_{t} \perp \tau_{t}\left(D_{t} \perp \hat{D}_{t}\right) .
$$

Here $\hat{D}_{t}$ denotes the numbers of permits that the government supplies to each ?rm. From the ?rms? pro?t maximization (evaluated market equilibrium), we can obtain

$$
\begin{aligned}
w_{t} & =A \alpha H_{t}^{\alpha \perp 1} D_{t}^{1 \perp \alpha}, \\
\tau_{t} & =A(1 \perp \alpha) H_{t}^{\alpha} D_{t}^{\perp \alpha} .
\end{aligned}
$$

Presuming that the market for permits clears at every moment: $D_{t}=\hat{D}_{t}$ for all $t$. Then $\pi_{t}=\tau_{t} D_{t}=A(1 \perp \alpha) H_{t}^{\alpha} D_{t}^{1 \perp \alpha}$.

\footnotetext{
${ }^{4}$ Subscript $t$ represents the level in period $t$ throughout this paper.

${ }^{5}$ See Stokey (1998). In her model, the pro?ts are allocated to households because the ?rms are owned by households. However, the pro?ts become entrepreneur?s income in our model. We will explain this point later in detail.
} 
Let us consider consumers. Generation $t$ is de?ned as the people who are born in period $t$. We assume that individuals live for two periods and that each has one child. Without loss of generality, we assume that the number of each generation is unity. During the period of youth, individuals accumulate human capital and do not work. The production function of human capital of generation $t$ is speci?ed as

$$
H_{t+1}=B H_{t}^{\beta} z_{t}^{1 \perp \beta}
$$

where $B$ is the parameter and $0<\beta<1$. The $H_{t}$ on the right-hand-side denotes positive externalities from the human capital of parents (generation $t \perp 1$ ), and $z_{t}$ is the educational outlay from the parents. Education cost of young people (generation $t$ ) is paid by their parents (generation $t \perp 1$ ). Note also that there is no decision making when they are young.

Each individual can only work during the second period of life. They supply human capital inelastically, earn a wage, and allocate their income to consumption and education outlay of their children. It is assumed that the labor market clears at every moment. We also assume that utility of the representative individual depends on consumption and the parents? education expenditure on the child. ${ }^{6}$ We specify the expected utility of an individual in generation $t$ (which is represented as $U_{t}^{I}$ ) as

$$
U_{t}^{I}=\phi_{1} \log c_{t+1}+\left(1 \perp \phi_{1}\right) \log z_{t+1}+\phi_{2} \log E_{t+1},
$$

where $c_{t}$ signi?es consumption and $z_{t}$ denotes the education outlay to their children. Also, $\phi_{1}\left(0<\phi_{1}<1\right)$ and $\phi_{2}\left(\phi_{2}>0\right)$ are the parameters.

In addition, $E_{t}$ represents the environmental quality. We assume that the dynamic behavior of environmental quality is speci?ed as

$$
E_{t+1}=b_{1} E_{t} \perp b_{2} D_{t},
$$

where $b_{1}>1$ and $b_{2}>0$. The stock of the environmental good has the ability to renew itself. The rate of renewal is given as function $b_{1} E_{t}$. However, pollution causes environmental damage. One unit of pollution spoils $b_{2}$ units of environmental quality. Therefore, the net rate of change of the stock of the environment is given as (6).

Let us consider generation $t \perp 1$. They accumulate their human capital in period $t \perp 1$ and work in period $t$. Their budget constraint is given as $w_{t} H_{t}=c_{t}+z_{t}$. Individuals maximize their utility (5) ${ }^{7}$ subject to the budget constraint, taking $E_{t}$ as given. From the individuals? utility maximization, we can obtain

$$
\begin{aligned}
c_{t} & =\phi_{1} w_{t} H_{t}, \\
z_{t} & =\left(1 \perp \phi_{1}\right) w_{t} H_{t} .
\end{aligned}
$$

\footnotetext{
${ }^{6}$ See Glomm and Ravikumar (1992), Galor and Moav (2004), and others.

${ }^{7}$ Note that the utility of an individual in generation $t \perp 1$ is given as

$$
U_{t \perp 1}^{I}=\phi_{1} \log c_{t}+\left(1 \perp \phi_{1}\right) \log z_{t}+\phi_{2} \log E_{t} .
$$
}


From Eqs. (2), (4), and (8), we can obtain the following:

$$
\begin{aligned}
H_{t+1} & =B H_{t}^{\beta}\left(\left(1 \perp \phi_{1}\right) w_{t} H_{t}\right)^{1 \perp \beta} \\
& =B H_{t}^{\beta}\left(A \alpha\left(1 \perp \phi_{1}\right) H_{t}^{\alpha} D_{t}^{1 \perp \alpha}\right)^{1 \perp \beta} \\
& =B\left(A \alpha\left(1 \perp \phi_{1}\right)\right)^{1 \perp \beta} H_{t}^{1 \perp(1 \perp \alpha)(1 \perp \beta)} D_{t}^{(1 \perp \alpha)(1 \perp \beta)} .
\end{aligned}
$$

Next, we will speci?cally examine the entrepreneur. ${ }^{8}$ We assume that the utility of the entrepreneur in period $t$ depends only on the pro?t of the ?rm in period $t$ (we implicitly assume that entrepreneurs are short lived). We specify the utility of entrepreneur $\left(U_{t}^{F}\right)$ as

$$
U_{t}^{F}=\log \pi_{t}=\log \left((1 \perp \alpha) Y_{t}\right)
$$

\section{Environmental Policy}

In this section, we consider government policy. A government supplies a permit to control the pollution. We assume that the government is short-lived and that its objective is to maximize utility $\left(U_{t}^{G}\right)$, which is de?ned as

$$
U_{t}^{G}=U_{t \perp 1}^{I}+U_{t}^{I}+\phi_{3} U_{t}^{F}+f\left(M_{t}, Y_{t}\right)
$$

where $U_{t}^{I}$ and $U_{t}^{F}$ are de?ned in the previous section. Also, $M_{t}$ signi?es the political donation and $f\left(M_{t}, Y_{t}\right)$ denotes the net bene?t of such a donation. In this section, we speci?cally examine the case in which $M_{t}=0$. In other words, we analyze the case in which no political corruption exists. Therefore, the utility of the government in this is given as $U_{t}^{G}=U_{t \perp 1}^{I}+U_{t}^{I}+\phi_{3} U_{t}^{F}$ because we assume $f\left(0, Y_{t}\right)=0$. In Sect. 4, we will discuss problems related to political corruption in detail. Parameter $\phi_{3}$ is the relative weight that the politicians assign to the utility of the entrepreneur. The following equations must hold:

$$
\begin{aligned}
c_{t+1}= & \phi_{1} \alpha Y_{t+1} \\
= & A \alpha \phi_{1} H_{t+1}^{\alpha} D_{t+1}^{1 \perp \alpha} \\
= & A \alpha \phi_{1} D_{t+1}^{1 \perp \alpha}\left[B\left(A \alpha\left(1 \perp \phi_{1}\right)\right)^{1 \perp \beta} H_{t}^{1 \perp(1 \perp \alpha)(1 \perp \beta)} D_{t}^{(1 \perp \alpha)(1 \perp \beta)}\right]^{\alpha} \\
= & (A \alpha)^{1+\alpha \perp \alpha \beta} \phi_{1}\left(1 \perp \phi_{1}\right)^{\alpha(1 \perp \beta)} \\
& \perp B^{\alpha} D_{t+1}^{1 \perp \alpha} H_{t}^{\alpha(1 \perp(1 \perp \alpha)(1 \perp \beta))} D_{t}^{\alpha(1 \perp \alpha)(1 \perp \beta)} \\
z_{t+1}= & \left(1 \perp \phi_{1}\right) \alpha Y_{t+1} \\
= & A \alpha\left(1 \perp \phi_{1}\right) H_{t+1}^{\alpha} D_{t+1}^{1 \perp \alpha}
\end{aligned}
$$

\footnotetext{
${ }^{8}$ Acemoglu et al. (2006) describe a model in which collusion between capitalists and entrepreneurs undermines the economy.
} 


$$
\begin{aligned}
& =A \alpha\left(1 \perp \phi_{1}\right) D_{t+1}^{1 \perp \alpha}\left[B\left(A \alpha\left(1 \perp \phi_{1}\right)\right)^{1 \perp \beta} H_{t}^{1 \perp(1 \perp \alpha)(1 \perp \beta)} D_{t}^{(1 \perp \alpha)(1 \perp \beta)}\right]^{\alpha} \\
& =\left(A \alpha\left(1 \perp \phi_{1}\right)\right)^{1+\alpha \perp \alpha \beta} B^{\alpha} D_{t+1}^{1 \perp \alpha} H_{t}^{\alpha(1 \perp(1 \perp \alpha)(1 \perp \beta))} D_{t}^{\alpha(1 \perp \alpha)(1 \perp \beta)} .
\end{aligned}
$$

The government in period $t$ looks ahead to the subsequent period because the utility of each young voter depends on $c_{t+1}$ and $E_{t+1}$. Following Verbon and Verhoeven (1992), Meijdam and Verbon (1997), and Ono (2005), this paper assumes rational expectations and myopic decision making. Rational expectations mean that the shortlived government can estimate the environmental tax rate in the subsequent period accurately. Myopic decision making implies that the government does not consider the impact of current policies on future political decisions. These assumptions imply that the government chooses a level of pollution $D_{t}$, taking the level of pollution in the next period $D_{t+1}$ as given.

Let us consider the impact of the relaxation of environmental regulations (the increase in the supply of the emissions credits). First, it raises the wages and consumption of elderly worker. This effect increases the utility of each old voter. Second, it drives up pro?ts of the ?rm. This effect improves the utility of each entrepreneur. Third, it increases the consumption of period $t+1$ because human capital in period $t+1$ will drive up by such deregulation. This effect increases the utility of each young voter. Fourth, the environmental quality decreases in period $t+1$. Each young voter will be worse off by this effect.

The condition for the maximum is given as

$$
\frac{\phi_{4}}{D_{t}}=\frac{b_{2} \phi_{2}}{b_{1} E_{t} \perp b_{2} D_{t}},
$$

where $\phi_{4} \equiv(1 \perp \alpha)\left(1+\phi_{3}+\alpha(1 \perp \beta)\right)$. Then we can express the level of pollution (denoted as $D_{t}^{*}$ ) as

$$
D_{t}^{*}=\frac{b_{1} \phi_{4}}{b_{2}\left(\phi_{2}+\phi_{4}\right)} E_{t}
$$

The level of pollution will be higher when individuals do not care about the environment (lower $\phi_{2}$ ), when the regenerative ability of the environment is high (higher $b_{1}$ ), when pollution does not severely affect the environment (lower $b_{2}$ ), when the pro?t rate is high (lower $\alpha$ ), and when the relative weight the politicians attach to the utility of entrepreneur is high (higher $\phi_{3}$ ). From Eqs. (6) and (13), we obtain

$$
E_{t+1}=\frac{b_{1} \phi_{2}}{\phi_{2}+\phi_{4}} E_{t} \equiv g^{*} E_{t}
$$

Here we de?ne $g^{*} \equiv \frac{b_{1} \phi_{2}}{\phi_{2}+\phi_{4}}$. The growth rate of $E_{t}$ is $g^{*} \perp 1$ for all $t$. It is assumed that $g^{*}>1$. That is, $E_{t}$ improves over time. Furthermore, from Eqs. (9) and (13), we obtain

$$
H_{t+1}=B\left(A \alpha\left(1 \perp \phi_{1}\right)\right)^{1 \perp \beta} H_{t}^{1 \perp(1 \perp \alpha)(1 \perp \beta)}\left(\frac{b_{1} \phi_{4}}{b_{2}\left(\phi_{2}+\phi_{4}\right)} E_{t}\right)^{(1 \perp \alpha)(1 \perp \beta)} .
$$


Fig. 1 The relationship between $q_{t+1}$ and $q_{t}$

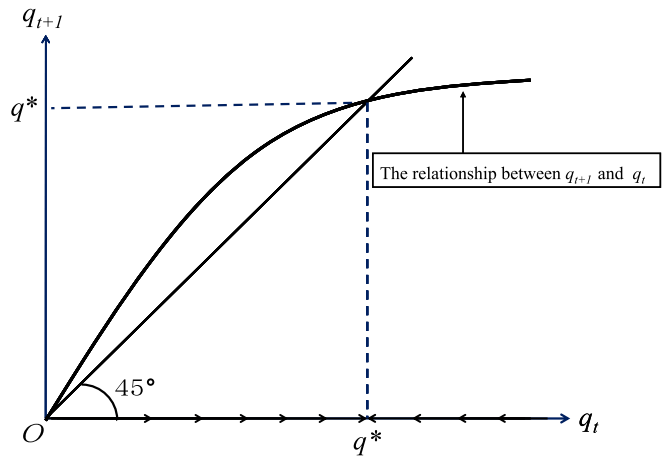

We de?ne $\frac{H_{t}}{E_{t}} \equiv q_{t}$. Equations (14) and (15) imply that

$$
\begin{aligned}
q_{t+1}= & B\left(A \alpha\left(1 \perp \phi_{1}\right)\right)^{1 \perp \beta}\left(\frac{\phi_{2}+\phi_{4}}{b_{1}}\right)^{1 \perp(1 \perp \alpha)(1 \perp \beta)} \\
& \perp\left(\phi_{2}\right)^{\perp 1}\left(\frac{\phi_{4}}{b_{2}}\right)^{(1 \perp \alpha)(1 \perp \beta)} q_{t}^{1 \perp(1 \perp \alpha)(1 \perp \beta)} .
\end{aligned}
$$

The dynamic behavior of $q_{t}$ is given as (16). We can show that $q_{t}=q_{t+1}$ in the long run because $0<1 \perp(1 \perp \alpha)(1 \perp \beta)<1$ (see Fig. 1). This steady state is unique and stable. In the steady state, $\frac{H_{t+1}}{H_{t}}=g^{*}$. Therefore, the growth rate of the ?nal good is also given by $g^{*}$. The initial values of $q_{t}$ do not play an important role in our model.

We have not considered the range of $D_{t}$ until this point. However, as pointed out by Copeland and Taylor (1994), and Stokey (1998), the contribution of $D_{t}$ to $Y_{t}$ must be limited by a ceiling. Suppose that $D_{t} \leq d Y_{t}$. Copeland and Taylor (1994), and Stokey (1998) make similar assumptions. We assume that $d$ - is relatively large and the existence of this assumption does not affect our results thus far.

We can show that human capital accumulation is necessary for $\frac{Y_{t+1} \perp Y_{t}}{Y_{t}}>0$ if we assume $D_{t} \leq d Y_{t}$. To prove this, suppose that $B=0$ and $\beta=1$. Then $H_{t}=H_{0}$ for all $t$. Suppose also that $\frac{b_{1} \phi_{2}}{\phi_{2}+\phi_{4}}>1$ (see Eq. (14)). In this case the $D_{t}$ come at $d Y_{t}$ (note that $\left.D_{t} / d Y_{t}=D_{t}^{\alpha} / A H_{0}^{\alpha}\right)$ and the growth rates of $Y_{t}$ and $E_{t}$ become 0 in the long run. Human capital accumulation play an essential role in our model when $D_{t} \leq d Y_{t}$. In this paper, we would like to analyze how political corruption affects growth rate and environment. So, considering the human capital accumulation is necessary in our model.

\section{Corruption and Political Donation}

In the analysis presented above, we did not take political corruption into consideration. Several studies have, however, pointed to the possibility that political problems are detrimental to economic growth. For example, Krusell and Rios-Rull (1996) argue that an important role is played by vested interests in determining policies. They 
show that knowledge related to cottage technology sometimes blocks the adoption of new technology. Ehrlich and Lui (1999) construct a model in which each agent invests in political capital that affects income distribution. However, investment in political capital does not contribute to production or productivity increases, it counts for nothing from a social point of view. Acemoglu et al. (2006) show that interlocking relations among existing low-skilled managers (which can be interpreted as low productivity industries), capitalists (which can be interpreted as owners of the ?rms or ?nancial sectors), and government might bring about the delay of changes in the industrial structure. In these models, corruption tends to affect the steady state of the economy. However, these models do not consider environmental problems or bargaining between government and the private sector to affect environmental policies.

In this section, we introduce an interest group that offers a political donation to a government to head off the introduction of a strict environmental policy. Here, we assume that the entrepreneurs can form an interest group and affect government policies. ${ }^{9}$ The net pro?t of entrepreneurs is given as $(1 \perp \alpha) Y_{t} \perp M_{t}$ (where $M_{t}$ denotes the political donation). Therefore, the utility of representative entrepreneur is given as $\log \left[(1 \perp \alpha) Y_{t} \perp M_{t}\right]$. The utility of the government is de?ned as

$$
U_{t}^{G}=U_{t \perp 1}^{I}+U_{t}^{I}+\phi_{3} U_{t}^{F}+f\left(M_{t}, Y_{t}\right) .
$$

In that equation, $f\left(M_{t}, Y_{t}\right)$ represents the net bene?t of political donation. ${ }^{10} \mathrm{We}$ assume that $f\left(0, Y_{t}\right)=0$ for all $Y_{t}$. In Sects. 2 and 3, we do not consider political donations (that is, $M_{t}=0$ ). If $M_{t}=0$, Eq. (17) is equivalent to $U_{t}^{G}=U_{t \perp 1}^{I}+U_{t}^{I}+\phi_{3} U_{t}^{F}$. It is also assumed that a risk of taking a donation exists because a collusive relation between the interest group and government might not be supported by voters. We assume that the risk of accepting a donation increases with $Y_{t}$. Economic development increases the government?s risk of taking a donation: we assume $\frac{\partial f}{\partial M}>0$ and $\frac{\partial f}{\partial Y}<0$. The donation might be regarded as a bribe. In many countries, bribes are illegal in general. Bribery scandals might engender a change of government. The government of?cials might be arrested for corruption.

Figure 2 shows a positive correlation between per-capita $\mathrm{GDP}^{11}$ and corruption perceptions index (CPI) published by Transparency International a non-governmental organization that monitors corporate and political corruption in international development (Transparency International 2009). Corruption is de?ned as the abuse of entrusted power for private gain. A higher score of the index indicates less corruption. The highest (lowest) value is de?ned as $10(0)$. The results show that seven out of every ten countries (and nine out of every ten developing countries) have an index of

\footnotetext{
${ }^{9}$ Grossman and Helpman (1994) consider the effect of the interest groups. Acemoglu et al. (2006) consider the case in which old low-skill managers and capitalists entered into a collusive agreement. Ehrlich and Lui (1999) discuss the situation in which each agent (individuals or bureaucrat) invests not only in human capital but also in political capital, which affects income redistribution. Aidt et al. (2008) construct a model in which the government sets a tax rate to maximize its net bene?t. In his model, raising the tax rate increases the share that the government can obtain, but it decreases the tax base because some workers begin to move to the informal sector.

${ }^{10}$ Downs (1957) assumes that the sole motive behind government policy formulation is the winning of elections. He did not consider rent-seeking behavior of the government.

${ }^{11}$ We use data obtained from the World Bank (2011).
} 
Fig. 2 The relationship between log (per capita GDP) and $\log$ (corruption perceptions index)

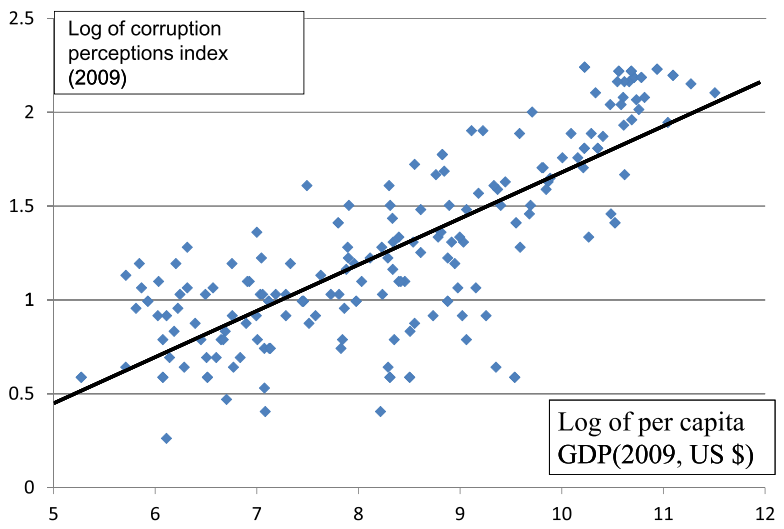

fewer than 5 points out of 10 . We present a plot showing the data of 168 countries in Fig. 2.

Lambsdorff (2007) shows that an improvement in the CPI by one point increases average income by 4 percentage points because appropriate institutions increase capital in?ows and raise productivity. ${ }^{12}$

This might imply that rich countries tend to have cleaner government, fair institutions, and appropriate laws. If so, the risk of taking political donations might increase with per-capita income because citizens in the developed countries call on the rectitude of government. To re?ect this point, we assume that the net bene?t of political donation increases with $M_{t}$ and decreases with $Y_{t}$. In this paper, we assume that $f\left(M_{t}, Y_{t}\right) \equiv \gamma \frac{M_{t}}{Y_{t}}$. Therefore, the utility of the government is given as $U_{t}^{G}=U_{t \perp 1}^{I}+U_{t}^{I}+\phi_{3} U_{t}^{F}+\gamma \frac{M_{t}}{Y_{t}}$.

We assume that $M_{t}$ and $D_{t}$ are determined endogenously through a process of bargaining between the government and the private ?rm. In this case, the government and the ?rm try to arrive at a cooperative outcome through mutual agreement. Available to them are a set of outcomes from which they can choose and a disagreement outcome, i.e., the outcome that is obtained when the government and the ?rm fail to arrive at an agreement (see Nash 1953 and Osborne and Rubinstein 1990). In this paper, the bargaining solution is to determine $\tau_{t}$ and $D_{t}$ to maximize

$$
\Delta U_{t}^{F} \perp \Delta U_{t}^{G}
$$

where $\Delta U_{t}^{F}$ and $\Delta U_{t}^{G}$ are de?ned as

$$
\begin{aligned}
\Delta U_{t}^{F}= & \log \left[(1 \perp \alpha) A H_{t}^{\alpha} D_{t}^{1 \perp \alpha} \perp M_{t}\right] \perp \log \left[(1 \perp \alpha) A H_{t}^{\alpha}\left(D_{t}^{*}\right)^{1 \perp \alpha}\right], \\
\Delta U_{t}^{G}= & \phi_{4} \log D_{t}+\phi_{2} \log \left(b_{1} E_{t} \perp b_{2} D_{t}\right)+\gamma \frac{M_{t}}{Y_{t}} \\
& \perp \phi_{4} \log D_{t}^{*} \perp \phi_{2} \log \left(b_{1} E_{t} \perp b_{2} D_{t}^{*}\right)
\end{aligned}
$$

\footnotetext{
${ }^{12}$ Data used in Lambsdorff (2007) are the older version. His book was published in 2007. Kurtzman et al. (2004) use the opacity index (another index that considers the institutions of the economy) and derive similar results.
} 
Therein, $D_{t}^{*}$ is given as (13). The conditions for the maximum are expressed as

$$
\begin{aligned}
\frac{(1 \perp \alpha)^{2} Y_{t} D_{t}^{\perp 1}}{(1 \perp \alpha) Y_{t} \perp M_{t}} \perp \Delta U_{t}^{G}+\left(\frac{\phi_{4}}{D_{t}} \perp \frac{b_{2} \phi_{2}}{b_{1} E_{t} \perp b_{2} D_{t}}\right) \perp \Delta U_{t}^{F}=0, \\
\frac{\perp 1}{(1 \perp \alpha) Y_{t} \perp M_{t}} \perp \Delta U_{t}^{G}+\gamma \frac{1}{Y_{t}} \perp \Delta U_{t}^{F}=0 .
\end{aligned}
$$

Equations (20) and (21) imply

$$
\frac{\phi_{4}+\gamma(1 \perp \alpha)^{2}}{D_{t}}=\frac{\phi_{2}}{b_{1} E_{t} \perp b_{2} D_{t}},
$$

which suggests that

$$
D_{t}^{1}=\frac{b_{1}\left[\phi_{4}+\gamma(1 \perp \alpha)^{2}\right]}{b_{2}\left[\phi_{2}+\phi_{4}+\gamma(1 \perp \alpha)^{2}\right]} E_{t},
$$

where $D_{t}^{1}$ is the pollution discharged in this situation. The pollution is more emitted (and differs from the optimal values) when the marginal bene?t of the political donation is high (larger $\gamma$ ) and pro?t rate is high (lower $\alpha$ ). In this case, dynamic behavior of $E_{t}$ is given as

$$
E_{t+1}=\frac{b_{1} \phi_{2}}{\phi_{2}+\phi_{4}+\gamma(1 \perp \alpha)^{2}} E_{t} \equiv\left(g^{1}\right) E_{t} .
$$

Here $g^{1} \equiv \frac{b_{1} \phi_{2}}{\phi_{2}+\phi_{4}+\gamma(1 \perp \alpha)^{2}}$. In the steady state, the growth rates of $E_{t}, H_{t}, Y_{t}$ are the same and are denoted as $g^{1} \perp 1$. From Eqs. (14) and (24), we know that $g^{*}>g^{1}$.

The intuition behind these results is as follows. Corruption increases the total amount of pollution because the government accepts political donations in exchange for the extra issuance of permits. An increase in pollution bumps the total output because $Y_{t}$ is positively correlated with $D_{t}$ (see Eq. (1)). So, corruption allows the economy to grow faster in period $t$. However, environmental stock decreases because $E_{t+1}$ is negatively correlated with $D_{t}$ (see Eq. (6)). So corruption has two opposite effects on $D_{t+1}$. First, corruption tends to increase $D_{t+1}$ because the government issues more permits for a given $E_{t+1}$. On the other hand, corruption in period $t$ decreases $E_{t+1}$ and this reduces $D_{t+1}$ (see Eq. (23)). The latter negative effects predominate eventually and the growth rate settles down at a lower steady state rate.

Figure 3 shows the relation between $g^{1}$ and $\gamma \cdot g^{1}$ is correlated negatively with $\gamma$. The growth rate is positive if $\gamma$ is small, although the growth rate is lower than $g^{*}$. However, $g^{1}$ becomes smaller than 0 if $\gamma>\hat{\gamma}$, where $\hat{\gamma}$ is de? ned as follows:

$$
\hat{\gamma} \equiv \frac{\left(b_{1} \perp 1\right) \phi_{2} \perp \phi_{4}}{(1 \perp \alpha)^{2}} .
$$

The growth rates of $Y_{t}, H_{t}$, and $E_{t}$ are given by $g^{1}$. In fact, $g^{1}$ becomes positive (negative) if and only if $\gamma<\hat{\gamma}(\gamma>\hat{\gamma})$. Political corruption engenders economic 
Fig. 3 The relationship between $\gamma$ and $g$

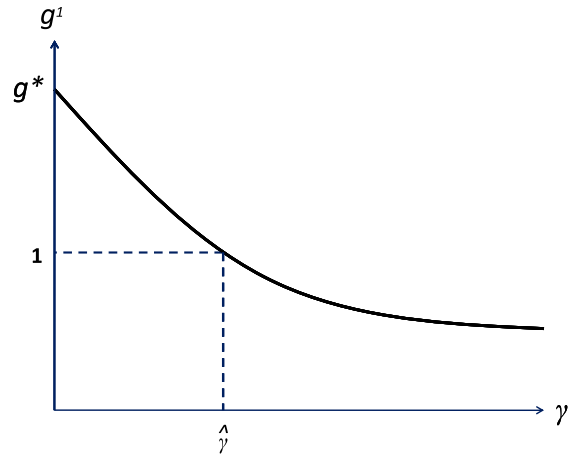

stagnation. Therefore, preventing politicians? or government of?cials? unfair meddling in government affairs might be necessary to achieve sustainable growth. Lopez and Mitra (2000) also assume that environmental policy and the amount of political donations are determined by bargaining between ?rms and government. In their model, corruption is unlikely to preclude the possibility of sustainable growth, although the pollution levels corresponding to corrupt behavior are always above the socially optimal level. In our model, this is no longer true. The long-run growth rate might become negative if the economy is rife with corruption.

Hall and Jones (1999) insist that the difference in output per worker and per-capita income are driven by differences in social infrastructure across countries. They de?ne social infrastructure as institutions and government policies that determine economic environment within which individuals accumulate skills, ?rms accumulate capital and engage in product activity. They conclude that per-capita output is positively related with social infrastructure. If we can relate uncorrupt government (in this case, $\gamma$ is small) to one feature of desirable social infrastructure, then our results might support the contention of Hall and Jones (1999).

\section{Concluding Remarks}

In this study, we extend a simple overlapping-generations model to consider the sustainability of growth. Our model includes environmental problems and political corruption. In many growth models that incorporate the environment, it is assumed that there exists an altruistic government that enforces the environmental policy to maximize the utility of households or social welfare. In many previous studies, the conditions for sustainable growth are derived based on this assumption.

In the ?rst part of this paper, we assumed that no political corruption exists. In this case, output per worker, human capital, and environmental quality grow at a positive rate in the steady state. Next, we integrated the politico-economic problems into the model because many earlier studies that examine environment and economic growth do not address political problems. We analyze the case in which the government accepts a political donation and relaxes an environmental regulation. We assume that environmental policy is determined endogenously through a process of bargaining 
between the government and the entrepreneur. This paper showed that the interlocking relations between the government and the interest group lower the growth rate and might cause economic stagnation. Lopez and Mitra (2000) show that corruption is unlikely to preclude the possibility of sustainable growth, although the pollution levels corresponding to corrupt behavior are always above the socially optimal level. In our model, this is no longer true. The long-run growth rate might become negative if the economy is rife with corruption.

\section{Competing Interests}

The author declares that he has no competing interests.

Acknowledgements This work was supported by JSPS KAKENHI Grant Number 25245042. I am grateful to Keisuke Osumi, Hikaru Ogawa, Kenichiro Ikeshita, Masayuki Sato, Shintaro Nakagawa, and two anonymous referees for their helpful comments. I would also like to express my appreciation to the participants in some conferences (The 9th World Congress of the Regional Science Association International held at Timisoara, Romania, and Seminars held at Kagoshima University and Japan Women?s University) who made valuable suggestions on earlier versions of this paper. Needless to say, all remaining errors are mine.

\section{References}

Acemoglu D, Aghion P, Zilibotti F (2006) Distance to frontier, selection, and economic growth. J Eur Econ Assoc 4:37?74

Aghion P, Howitt P (1992) A model of growth through creative destruction. Econometrica 60(2):323?351

Aghion P, Howitt P (1998) Endogenous growth theory. MIT Press, Cambridge

Aidt TS (1998) Political internalization of economic externalities and environmental policy. J Public Econ 69:1?16

Aidt TS, Dutta J, Senac V (2008) Governance regimes, corruption and growth: theory and evidence. J Comp Econ 36:195?220

Bovenberg A, Heijdra B (2002) Environmental abatement and intergenerational distribution. Environ Resour Econ 23(1):45?84

Copeland BR, Taylor MS (1994) North-south trade and the environment. Q J Econ 109:755?787

Damania R, Fredriksson PG, List JA (2003) Trade liberalization, corruption, and environmental policy formation: theory and evidence. J Environ Econ Manag 46:490?512

Diamond PA (1965) National debt in a neoclassical growth model. Am Econ Rev 55:1126?1150

Downs A (1957) An economic theory of democracy. Harper \& Row, New York

Ehrlich I, Lui FT (1999) Bureaucratic corruption and endogenous economic growth. J Polit Econ 107:S270?S293

Fredriksson PG (1997) The political economy of pollution taxes in a small open economy. J Environ Econ Manag 33:44?58

Galor O, Moav O (2004) From physical to human capital accumulation: inequality and the process of development. Rev Econ Stud 71:1001?1026

Glomm G, Ravikumar B (1992) Public versus private investment in human capital: endogenous growth and income inequality. J Polit Econ 100(4):818?834

Grossman GM, Helpman E (1994) Protections for sale. Am Econ Rev 84:833?850

Hall RE, Jones CI (1999) Why do some countries produce so much more output per worker than others. Q J Econ 114:83?116

John A, Pecchenino R (1994) An overlapping generations model of growth and the environment. Econ J 104:1393? 1410

John A, Pecchenino R, Schimmelpfennig D, Schreft S (1995) Short-lived agents and the long-lived environment. J Public Econ 58:127?141 
Jones L, Manuelli R (2001) Endogenous policy choice: the case of pollution and growth. Rev Econ Dyn 4:369?405

Krusell P, Rios-Rull JV (1996) Vested interests in a positive theory of stagnation and growth. Rev Econ Stud 63:301?329

Kurtzman J, Yago G, Phumiwasana T (2004) The global costs of opacity: measuring business and investment risk worldwide. MIT Sloan Manag Rev 46(1):38?44

Lambsdorff JG (2007) The institutional economics of corruption and reform: theory, evidence and policy. Cambridge University Press, Cambridge

Lopez R, Mitra S (2000) Corruption, pollution, and the Kuznets environment curve. J Environ Econ Manag 40:137? 150

Lucas RE Jr (1988) On the mechanics of economic development. J Monet Econ 22:3?42

Meijdam L, Verbon HAA (1997) Aging and public pensions in an overlapping-generations model. Oxf Econ Pap 49:29?42

Nash JF (1953) Two person cooperative games. Econometrica 21:128?140

Osborne MJ, Rubinstein A (1990) Bargaining and markets. Academic Press, San Diego

Ono T (2005) The political economy of environmental taxes with an aging population. Environ Resour Econ 30:165?194

Romer PM (1990) Endogenous technological change. J Polit Econ 94:S71?S102

Stokey NL (1998) Are there limits to growth? Int Econ Rev 39:1?32

Transparency International (2009) Corruption perceptions index 2009. http://www.transparency.org/ research/cpi/cpi2009/0/

Verbon HAA, Verhoeven MJM (1992) Decision making on pension schemes under rational expectations. J Econ 56:71?97

Wagner T (1998) Limits and cycles of environmental policy. Environ Resour Econ 11:155?175

World Bank (2011) World development indicators. World Bank, Washington 